\title{
Global stratospheric hydrogen peroxide distribution from MIPAS-Envisat full resolution spectra compared to KASIMA model results
}

\author{
S. Versick ${ }^{1,2}$, G. P. Stiller ${ }^{1}$, T. von Clarmann ${ }^{1}$, T. Reddmann ${ }^{1}$, N. Glatthor ${ }^{1}$, U. Grabowski ${ }^{1}$, M. Höpfner ${ }^{1}$, \\ S. Kellmann ${ }^{1}$, M. Kiefer ${ }^{1}$, A. Linden ${ }^{1}$, R. Ruhnke ${ }^{1}$, and H. Fischer ${ }^{1}$ \\ ${ }^{1}$ Institute for Meteorology and Climate Research, Karlsruhe Institute of Technology, Germany \\ ${ }^{2}$ Steinbuch Centre for Computing, Karlsruhe Institute of Technology, Germany \\ Correspondence to: S. Versick (stefan.versick@kit.edu)
}

Received: 23 September 2011 - Published in Atmos. Chem. Phys. Discuss.: 20 December 2011

Revised: 10 May 2012 - Accepted: 11 May 2012 - Published: 6 June 2012

\begin{abstract}
MIPAS-ENVISAT full resolution spectra were analyzed to obtain a global distribution of hydrogen peroxide $\left(\mathrm{H}_{2} \mathrm{O}_{2}\right)$ in the stratosphere. $\mathrm{H}_{2} \mathrm{O}_{2}$ acts as reservoir gas for the $\mathrm{HO}_{\mathrm{x}}$ family $\left(=\mathrm{H}+\mathrm{OH}+\mathrm{HO}_{2}\right)$ and thus, observations of $\mathrm{H}_{2} \mathrm{O}_{2}$ provide a better understanding of the $\mathrm{HO}_{\mathrm{x}}$ chemistry in the atmosphere. A retrieval approach based on constrained least squares fitting was developed and applied to small dedicated spectral analysis windows with maximum $\mathrm{H}_{2} \mathrm{O}_{2}$ information and minimum contribution of interfering gases. Due to a low signal to noise ratio in the measured spectra single profiles cannot be used for scientific interpretation and about 100 profiles have to be averaged temporally or spatially. Our retrievals of $\mathrm{H}_{2} \mathrm{O}_{2}$ from MIPAS measurements provide meaningful results between approximately 20 and $60 \mathrm{~km}$. A possible impact by the high uncertainty of the reaction rate constant for $\mathrm{HO}_{2}+\mathrm{HO}_{2} \rightarrow \mathrm{H}_{2} \mathrm{O}_{2}+\mathrm{O}_{2}$ in our 3D-CTM KASIMA is discussed. We find best agreement between model and observations for applying rate constants according to Christensen et al. (2002), however, a mismatch in vertical profile shape remains. The observations were compared to the model results of KASIMA focusing on low to mid latitudes. Good agreement in spatial distribution and in temporal evolution was found. Highest vmr of $\mathrm{H}_{2} \mathrm{O}_{2}$ in the stratosphere were observed and modeled in low latitudes shortly after equinox at about $30 \mathrm{~km}$. The modelled diurnal cycle with lowest vmr shortly after sunrise and highest vmr in the afternoon is confirmed by the MIPAS observations.
\end{abstract}

\section{Introduction}

\subsection{Hydrogen Peroxide sources and sinks}

Odd hydrogen $\left(\mathrm{HO}_{\mathrm{x}}=\mathrm{H}+\mathrm{OH}+\mathrm{HO}_{2}\right)$ is one of the most important gas families in the Earth's atmosphere. It destroys ozone catalytically and is known as cleaning agent of the atmosphere. Hydrogen peroxide $\left(\mathrm{H}_{2} \mathrm{O}_{2}\right)$ acts as a reservoir gas for $\mathrm{HO}_{\mathrm{x}}$ and therefore plays an important role in atmospheric chemistry. It reduces the amount of the very reactive $\mathrm{HO}_{\mathrm{x}}$ radicals. The main source of $\mathrm{H}_{2} \mathrm{O}_{2}$ is the $\mathrm{HO}_{2}$ self-reaction:

$\mathrm{HO}_{2}+\mathrm{HO}_{2} \longrightarrow \mathrm{H}_{2} \mathrm{O}_{2}+\mathrm{O}_{2}$

Of minor importance is the three-body reaction:

$\mathrm{OH}+\mathrm{OH}+M \longrightarrow \mathrm{H}_{2} \mathrm{O}_{2}+M$

The main sink in the stratosphere is through photolysis:

$\mathrm{H}_{2} \mathrm{O}_{2}+h v \longrightarrow 2 \mathrm{OH}$

The reactions with $\mathrm{OH}$

$\mathrm{H}_{2} \mathrm{O}_{2}+\mathrm{OH} \longrightarrow \mathrm{H}_{2} \mathrm{O}+\mathrm{HO}_{2}$

and with atomic oxygen

$\mathrm{H}_{2} \mathrm{O}_{2}+\mathrm{O} \longrightarrow \mathrm{OH}+\mathrm{HO}_{2}$

destroy $\mathrm{H}_{2} \mathrm{O}_{2}$ to a smaller extent.

The photochemical lifetime of $\mathrm{H}_{2} \mathrm{O}_{2}$ varies from approximately 2 days in the lower stratosphere to a few hours in the mesosphere. It is assumed that $\mathrm{H}_{2} \mathrm{O}_{2}$ is approximately in 
photochemical equilibrium with $\mathrm{HO}_{\mathrm{x}}$ in a wide range of the middle atmosphere (Brasseur and Solomon, 2005).

Another possible source of $\mathrm{H}_{2} \mathrm{O}_{2}$ in the stratosphere is transport from the troposphere to the stratosphere. In the troposphere, $\mathrm{H}_{2} \mathrm{O}_{2}$ is enhanced within biomass burning plumes (Lee et al., 1997). Important sinks in the troposphere are washout by rain, reaction with dissolved $\mathrm{SO}_{2}$ (Seinfeld and Pandis, 2006) and heterogeneous processes on cloud particles (scavenging) (Holloway and Wayne, 2010).

\subsection{Hydrogen Peroxide measurements}

To date, there are only a few atmospheric measurements of hydrogen peroxide. Most of them are airborne measurements (e.g. Heikes et al., 1987; Gallagher et al., 1991), mountain top measurements (e.g. Olszyna et al., 1988), measurements at the ground (e.g. Ayers et al., 1992; Gnauk et al., 1997) or ship-borne measurements (e.g. Slemr and Tremmel, 1994) within the troposphere.

There are also some balloon-borne remote measurements in the stratosphere. Chance et al. (1996) measured a peak value of about $120 \mathrm{pptv}$ at an altitude of $32 \mathrm{~km}$ over New Mexico. Park and Carli (1991) obtained a slightly higher value at an altitude of $30 \mathrm{~km}$ over Texas. Both measurements are in the far infrared spectral region. Waters et al. (1981) obtained a much higher mixing ratio from a balloon-borne microwave sounder than the former mentioned authors.

Papandrea et al. (2005) derived profiles of $\mathrm{H}_{2} \mathrm{O}_{2}$ from MIPAS-Envisat measurements. They retrieved the logarithm of the volume mixing ratio (vmr) instead of the vmr, which avoids negative mixing ratios but can cause a positive bias when results are averaged.

The retrieval approach described in this paper was developed as to avoid biases as much as possible which may show up when data are averaged. We present global distributions of $\mathrm{H}_{2} \mathrm{O}_{2}$ and their seasonal and diurnal variation and compare them to the 3 dimensional Chemical Transport Model (3D-CTM) KASIMA.

\section{MIPAS-Envisat}

The Michelson Interferometer for Passive Atmospheric Sounding (MIPAS) is a limb-viewing Fourier transform infrared (FTIR) spectrometer measuring the emission of the Earth's atmosphere (Fischer and Oelhaf, 1996; Fischer et al., 2008). It was launched aboard the environmental satellite (Envisat) on 1 March 2002 into a sun-synchronous polar orbit. It covers a wide mid-infrared spectral region from 685 to $2410 \mathrm{~cm}^{-1}$. In its original measurement mode it was operated with a spectral resolution of $0.025 \mathrm{~cm}^{-1}$. This mode consisted of 17 altitude steps with tangent altitudes between 6 and $68 \mathrm{~km}$ (step-width $3 \mathrm{~km}$ between 6 and $42 \mathrm{~km}$ and at $47,52,60$, and $68 \mathrm{~km}$ ). In 2004 the spectral resolution had to be decreased to $0.0625 \mathrm{~cm}^{-1}$ due to an instrument failure.
At the same time the spatial resolution was improved. These so-called optimized resolution measurements are performed in numerous different operation modes.

Generation of calibrated, so-called level-1B radiance spectra, is performed by the European Space Agency (ESA) (Nett et al., 2002). The hydrogen peroxide retrievals described in this paper were performed with the retrieval processor of the Institut für Meteorologie und Klimaforschung (IMK) and the Instituto de Astrofisica de Andalucia (IAA) (von Clarmann et al., 2003) from the full spectral resolution measurements before March 2004.

\section{Model description}

We compare the measured $\mathrm{H}_{2} \mathrm{O}_{2}$ fields to the model results of KASIMA (Karlsruhe Simulation Model of the Middle Atmosphere). KASIMA is a 3D-CTM. It includes the stratospheric chemistry and is able to simulate physical and chemical effects in the middle atmosphere (Kouker et al., 1999; Ruhnke et al., 1999; Reddmann et al., 2001). The model is based on the solution of the primitive meteorological equations in spectral formulation and uses the pressure altitude $z$, with $z=-H \ln \left(p / p_{0}\right)$, as the vertical coordinate. Here $p$ is the pressure, $H(=7 \mathrm{~km})$ is the atmospheric-scale height and $p_{0}=1013 \mathrm{hPa}$. For the simulations in this paper we use a horizontal resolution of T21 $\left(5.6^{\circ} \times 5.6^{\circ}\right)$ and 63 layers reaching from 7 to $120 \mathrm{~km}$. Below $18 \mathrm{~km}$ the operational analysis from ECMWF (European Centre for Medium-Range Weather Forecasts) are used, from 18 to $48 \mathrm{~km}$ temperature, divergence and vorticity are relaxed to the ECMWF analysis. Between $48 \mathrm{~km}$ and the upper boundary the prognostic part of the model is used. A numerical time step of $12 \mathrm{~min}$ is used for the dynamic part of the model and a time step of 4 minutes for the chemistry part in the experiments. For $\mathrm{HO}_{\mathrm{x}}, \mathrm{NO}_{\mathrm{x}}$, $\mathrm{ClO}_{\mathrm{x}}, \mathrm{BrO}_{\mathrm{x}}$ and $\mathrm{O}_{\mathrm{x}}$ a family approach is used. The chemistry in KASIMA which is calculated up to $90 \mathrm{~km}$ on a rectangular grid includes all important species in the stratosphere as the oxygen-, nitrogen-, hydrogen-, chlorine- and bromine families. The 63 species in KASIMA interact by 127 gas phase reactions, 53 photolysis and 10 heterogeneous reactions. The reaction rates are from Sander et al. (2003). Photolysis rates are calculated online by the fast-j2-scheme from Brian and Prather (2002), supplemented by Lyman- $\alpha$ photolysis of $\mathrm{O}_{2}$, $\mathrm{CH}_{4}, \mathrm{CO}_{2}$, and $\mathrm{H}_{2} \mathrm{O}$ using the Lyman- $\alpha$ actinic flux parameterization of Reddmann and Uhl (2003).

\section{Hydrogen Peroxide spectral signatures}

In the mid-infrared spectral region, which is covered by the spectral range of MIPAS, hydrogen peroxide shows weak emission lines between about $1210 \mathrm{~cm}^{-1}$ and $1300 \mathrm{~cm}^{-1}$ (Fig. 1). All these lines belong to the $\mathrm{H}_{2} \mathrm{O}_{2} v_{6}$ band centered at $1266 \mathrm{~cm}^{-1}$. The spectroscopic data are taken from the latest update for $\mathrm{H}_{2} \mathrm{O}_{2}$ (based on measurements from (Perrin 


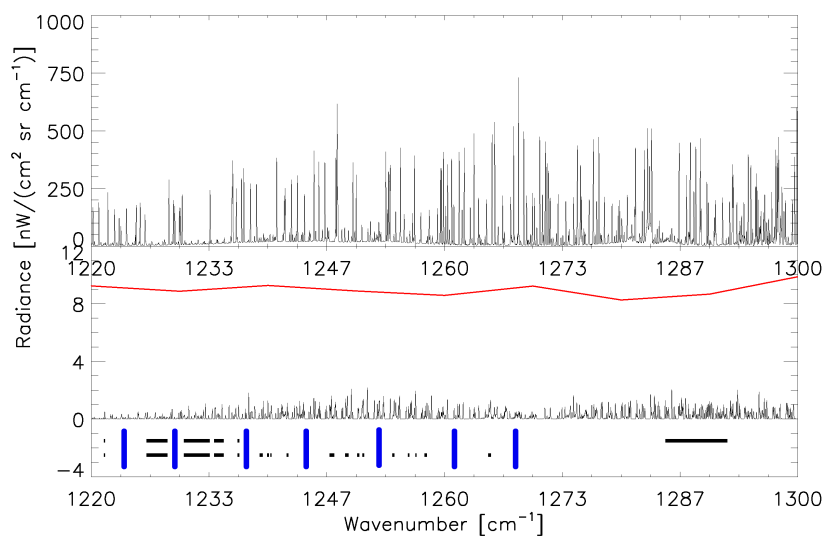

Fig. 1. Top: Simulated spectrum for tropical conditions and all gases included. Bottom: Contribution of Hydrogen Peroxide (note the different scale). Calculations are done for a tangent altitude of $35 \mathrm{~km}$. The red line in the bottom figure shows the typical spectral noise in the MIPAS measurements. Black horizontal bars represent the microwindows used for data analysis; bottom: below $44.5 \mathrm{~km}$ tangent altitude, top: above $44.5 \mathrm{~km}$ tangent altitude. All sub-microwindows in between a pair of vertical blue bars belong to one main microwindow.

et al., 1995) and (Klee et al., 1999)) in the HITRAN 2004 molecular spectroscopic database (Rothman et al., 2005). The challenge of the hydrogen peroxide retrieval is the very weak signal of the emission lines in comparison to the instrument noise which in this spectral region is much higher than the $\mathrm{H}_{2} \mathrm{O}_{2}$ signal (Fig. 1).

Figure 1 (top) shows that there are several strong spectral lines from other gases in the wavenumber range of the spectrum of hydrogen peroxide. These spectral lines are mainly from methane, nitrous oxide and water vapor transitions. The continuum like signature between $1230 \mathrm{~cm}^{-1}$ and $1260 \mathrm{~cm}^{-1}$ is due to $\mathrm{N}_{2} \mathrm{O}_{5}$ and that between $1275 \mathrm{~cm}^{-1}$ and $1290 \mathrm{~cm}^{-1}$ is due to $\mathrm{CF}_{4}$.

\section{Retrieval setup}

For the retrieval, 19 narrow spectral regions (19 submicrowindows which are combined to 8 main microwindows) have been selected by visual inspection between $1220 \mathrm{~cm}^{-1}$ and $1265 \mathrm{~cm}^{-1}$, which is the lower end of MIPAS band $\mathrm{B}$ and includes the P-branch of the $\mathrm{H}_{2} \mathrm{O}_{2} v_{6}$ band. These microwindows are applied up to tangent altitudes of $44.5 \mathrm{~km}$. The main criterion for the selection was high sensitivity to hydrogen peroxide and low interference by other gases (von Clarmann and Echle, 1998). Unfortunately the $\mathrm{R}$-branch could not be used in the lower stratosphere for our retrieval because the lines of the interfering gases are too dense. Above $44.5 \mathrm{~km}$ an additional microwindow from $1285 \mathrm{~cm}^{-1}$ to $1292 \mathrm{~cm}^{-1}$ was applied. The microwindows between $1237 \mathrm{~cm}^{-1}$ and $1265 \mathrm{~cm}^{-1}$ were not used in this al-
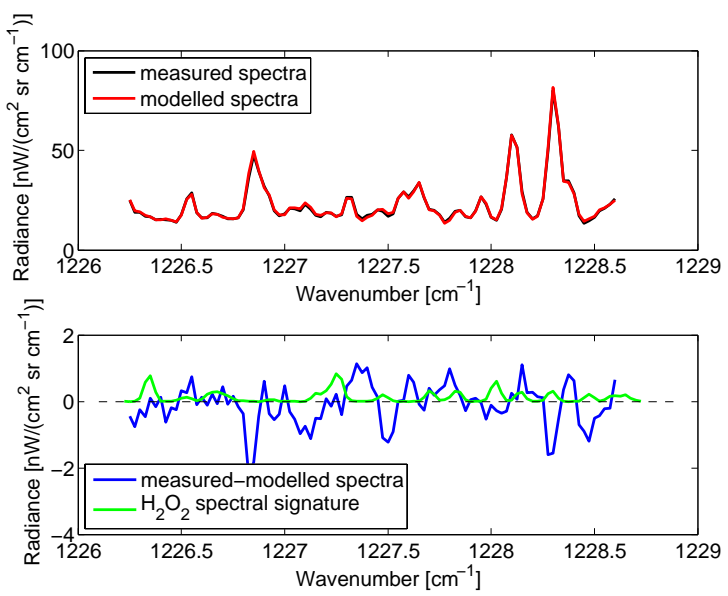

Fig. 2. Different spectra averaged between $20^{\circ} \mathrm{N}$ and $20^{\circ} \mathrm{S}$ in about $30 \mathrm{~km}$; Shown is main microwindow 2; Top: measured spectra (black), modelled spectra (red); Bottom: difference between measured and modelled spectra (blue), $\mathrm{H}_{2} \mathrm{O}_{2}$ spectral signature (green)

titude region due to absorption cross sections of $\mathrm{N}_{2} \mathrm{O}_{5}$ being potentially of low quality for low pressures. Since the hydrogen peroxide contribution is so small, the contribution of other gases needed to be considered and $\mathrm{HOCl}, \mathrm{N}_{2} \mathrm{O}_{5}$ and $\mathrm{COF}_{2}$ abundances had to be retrieved jointly in order to minimize related error propagation. $\mathrm{CH}_{4}, \mathrm{~N}_{2} \mathrm{O}, \mathrm{H}_{2} \mathrm{O}, \mathrm{O}_{3}$, $\mathrm{ClONO}_{2}$ and $\mathrm{HNO}_{3}$ had to be retrieved before the hydrogen peroxide retrieval in better suited spectral ranges and the results had to be considered in our $\mathrm{H}_{2} \mathrm{O}_{2}$ retrieval. For all the other gases in this spectral region climatological volume mixing ratio profiles were used.

In Fig. 2 a closer look at main microwindow 2 is shown. Our retrieval residual shown there is not correlated with the $\mathrm{H}_{2} \mathrm{O}_{2}$ signatures.

The retrieval procedure follows a scheme analog to that described by Rodgers (2000) but with a Tikhonov smoothing matrix (Tikhonov, 1963) instead of the climatological covariance matrix as constraint:

$$
\begin{aligned}
\boldsymbol{x}_{i+1}= & \boldsymbol{x}_{i}+\left(\mathbf{K}_{i}^{T} \mathbf{S}_{\boldsymbol{y}}^{-1} \mathbf{K}_{i}+\mathbf{R}\right)^{-1} \\
& \cdot\left[\mathbf{K}_{i}^{T} \mathbf{S}_{\boldsymbol{y}}^{-1}\left(\boldsymbol{y}-\mathbf{F}\left(\boldsymbol{x}_{i}\right)\right)-\mathbf{R}\left(\boldsymbol{x}_{i}-\boldsymbol{x}_{a}\right)\right]
\end{aligned}
$$

where $\boldsymbol{x}$ is the retrieval vector, $\mathbf{K}$ the partial derivatives of the spectral grid points with respect to the retrieval vector (Jacobian), $\mathbf{S}_{\boldsymbol{y}}$ is the covariance matrix representing measurement noise, $\mathbf{R}$ the regularization or constraint matrix, $\boldsymbol{y}$ the vector of measured spectral radiances used, $\mathbf{F}$ the forward model, $\boldsymbol{x}_{a}$ the a priori profile, and $i$ the iteration index. In the case of convergence problems, Eq. (1) is modified by inclusion of a Levenberg-Marquardt term (Levenberg, 1944; Marquardt, 1963) to force the iteration towards smaller but safer steps of the parameter update (see von Clarmann et al. (2003) for formal details). 
The grid used for the retrieval has an altitude spacing of $1 \mathrm{~km}$ up to $44 \mathrm{~km}$ and of $2 \mathrm{~km}$ between 44 and $70 \mathrm{~km}$. The tangent point spacing of MIPAS is $3 \mathrm{~km}$ and therefore coarser than our retrieval grid. To avoid retrieval instabilities as a consequence of this choice, the retrieval was stabilized by a (Tikhonov, 1963) type smoothing constraint in an altitudedependent implementation by (Steck, 2002). Due to the very low signal-to-noise ratio we had to choose a rather high regularization strength resulting in a low number of degrees of freedom. The regularization is stronger in the upper stratosphere. It is weakest in the middle stratosphere where we expect the maximum volume mixing ratio of $\mathrm{H}_{2} \mathrm{O}_{2}$. Lowest measurement altitudes used were around $20 \mathrm{~km}$ because otherwise oscillations in our profiles occured which were caused by unsuccessful fitting of measurements at lower altitudes and upward error propagation due to the retrieval scheme. The shortcoming of this retrieval approach is that we cannot derive information about $\mathrm{H}_{2} \mathrm{O}_{2}$ from the troposphere which would be interesting for the understanding of the ozone budget of the troposphere for which hydrogen peroxide plays an important role.

As initial guess the climatological profiles from Kiefer et al. (2002) and Remedios et al. (2007) were used. As a priori profile we use an all-zero profile to avoid any artificial structures in the hydrogen peroxide profile not caused by the measurements. It should be noted that this choice does not cause a systematic negative bias of the results because the absolute amount lies in the nullspace of our regularization matrix which constrains only the differences between adjacent profile points. The setting for microwindows, constraint and a-priori profiles are chosen time and latitude-independent. All variations of structures in the retrieved distributions originate from the measurements and are not artificial structures from the retrieval setup.

With this approach more than $99.9 \%$ of our $\mathrm{H}_{2} \mathrm{O}_{2}$ retrievals converge.

\section{Retrieval}

\subsection{Retrieval for synthetic spectra}

The retrieval setup was validated by retrieval of $\mathrm{H}_{2} \mathrm{O}_{2}$ from synthetic spectra. These spectra were calculated with the Karlsruhe Optimized and Precise Radiative transfer Algorithm (KOPRA) (Stiller et al., 2002). We used the $\mathrm{H}_{2} \mathrm{O}_{2}$ profile shown in Fig. 3. All the other gases were set to their climatological values.

With this calculated spectrum a retrieval as described in Section 5 was performed. The result is a profile of $\mathrm{H}_{2} \mathrm{O}_{2}$ (Fig. 3 red line) with a vertical resolution coarser than the input profile. Both profiles have their maximum in about the same altitude and differences are due to different vertical resolution. Results from real measurements are expected to be worse because of instrumental noise, probably less-than-

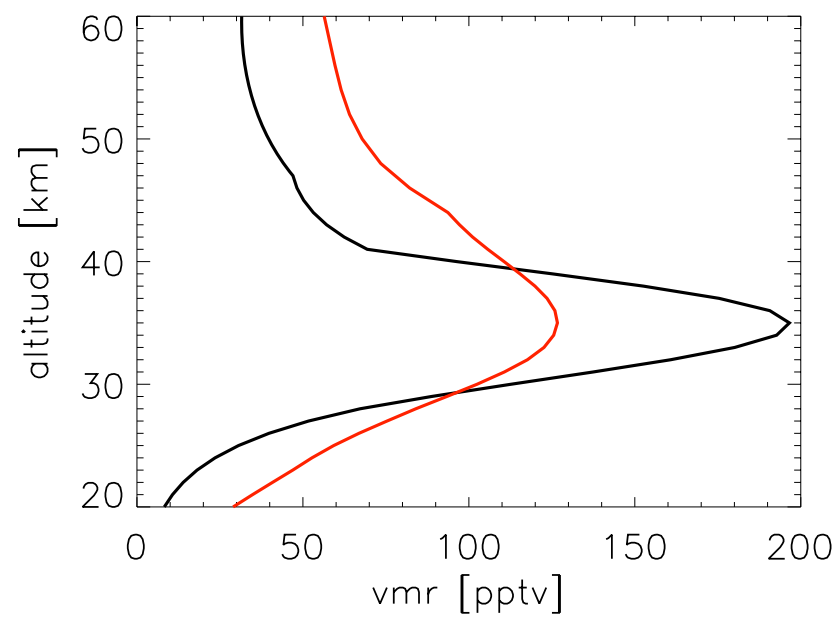

Fig. 3. Results for retrieval with synthetic spectra; black line: profile used to generate the synthetic measurements; red line: retrieval result.

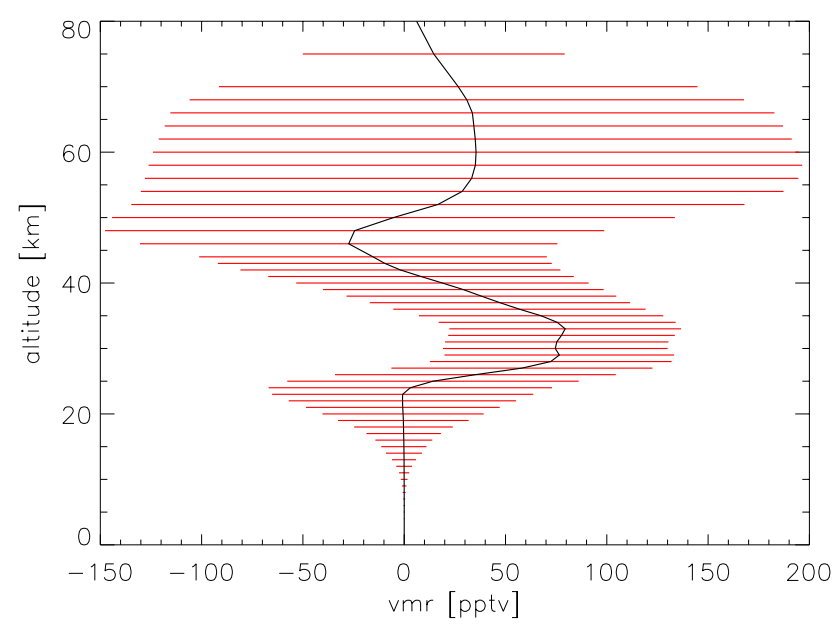

Fig. 4. Hydrogen peroxide retrieval result (solid line) (orbit 7791, 27 August 2003, tropics). Error bars represent propagated measurement noise.

perfect spectroscopic information of each gas (the same spectroscopy was used for the forward calculation and the retrieval) and potential contributions of gases not considered in our retrieval.

\subsection{Retrieval from measured spectra}

In a next step the retrieval procedure described above was applied to measured MIPAS spectra. Figure 4 shows an example for a single profile retrieval of hydrogen peroxide for MIPAS-Envisat orbit 7791 on 27 August 2003 at $3^{\circ} \mathrm{S} / 154^{\circ} \mathrm{W}$. The profile shows maximum values in the middle stratosphere of 80 parts per trillion by volume (pptv) and insignificant negative values in the upper stratosphere.

In our retrieval we accept negative values by intention, because high noise can result in negative retrieved mixing 


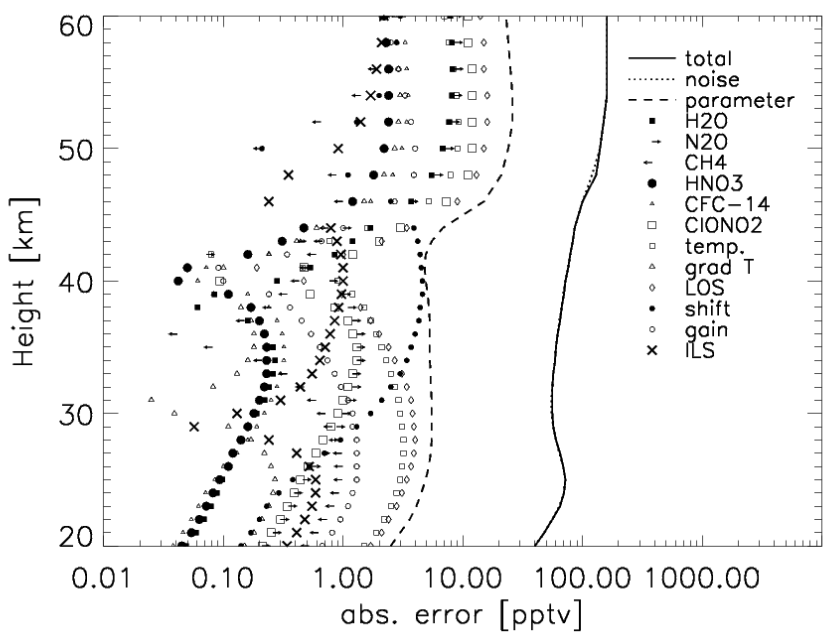

Fig. 5. Error analysis of hydrogen peroxide retrieval (orbit 7791, 27 August 2003, tropics). Error sources from top to bottom: total error (solid line), noise error (dotted line) (mostly overlapped by total error), total parameter error (dashed line) containing errors due to vmr uncertainties of other gases: $\mathrm{H}_{2} \mathrm{O}, \mathrm{N}_{2} \mathrm{O}, \mathrm{CH}_{4}, \mathrm{HNO}_{3}, \mathrm{CF}_{4}$ and $\mathrm{ClONO}_{2}$, error due to temperature uncertainty and uncertainty of the temperature gradient, line-of-sight (LOS) uncertainty, spectral shift uncertainty, gain calibration uncertainty, and residual uncertainty of the instrumental line shape (ILS).

ratios. A retrieval of the logarithm of volume mixing ratio as Papandrea et al. (2005) did would avoid negative, thus unphysical, values but would produce a positive bias in case of averaging. Smallest mean values retrieved by Papandrea et al. (2005) are slightly lower than 30 pptv. Assuming that the possible bias is constant with altitude would imply that the bias in their retrievals is less than about $10 \%$ of the maximal mixing ratio of $\mathrm{H}_{2} \mathrm{O}_{2}$.

\subsection{Error analysis}

The total expected error consists of the error due to measurement noise, called noise error below, parameter error and smoothing error (Rodgers, 2000).

For a single $\mathrm{H}_{2} \mathrm{O}_{2}$ profile the noise error is by far the largest. In the example error budget (Fig. 5) the total error is dominated by the noise error (total error and noise error are nearly identical in the figure). In the lower stratosphere the noise error is about 40 pptv and increases in the higher stratosphere to values of approximately $150 \mathrm{pptv}$. As the noise error can be assumed to be randomly distributed, averaging can be applied to reduce the statistical error. In this paper we used daily means or means of the whole time series for latitude bins of $5^{\circ}$.

The parameter error is less important for $\mathrm{H}_{2} \mathrm{O}_{2}$. It contains uncertainties of parameters of the forward calculations. For example, errors in the vmrs of interfering gases, which are used in the $\mathrm{H}_{2} \mathrm{O}_{2}$ retrieval, cause errors in the $\mathrm{H}_{2} \mathrm{O}_{2}$ retrieval. The largest error sources are uncertainties in $\mathrm{ClONO}_{2}, \mathrm{~N}_{2} \mathrm{O}$,
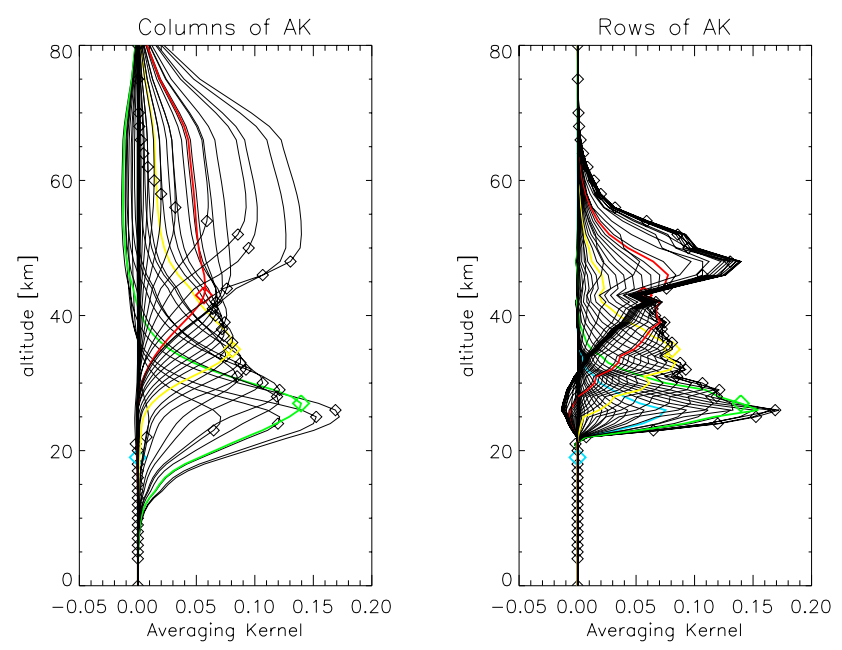

Fig. 6. Typical MIPAS Averaging Kernel (A) in the tropics for $\mathrm{H}_{2} \mathrm{O}_{2}$. Altitudes marked for better illustration: $19 \mathrm{~km}$ (turquois), $27 \mathrm{~km}$ (green), $35 \mathrm{~km}$ (yellow) and $43 \mathrm{~km}$ (red). The diamonds indicate the altitude the averaging kernels refer to.

and $\mathrm{H}_{2} \mathrm{O}$. The error due to uncertainty of $\mathrm{ClONO}_{2}$ is about 15 pptv in the higher stratosphere, $\mathrm{N}_{2} \mathrm{O}$ and $\mathrm{H}_{2} \mathrm{O}$ uncertainties are contributing with roughly $10 \mathrm{pptv}$ to the parameter error. Another important parameter error is the error due to temperature uncertainty which is about $10 \mathrm{pptv}$ in the upper stratosphere. In the polar regions the parameter error is much smaller (about 2 to 3 pptv) than elsewhere and does not play a role at all. This error is partly randomly distributed and partly systematic depending on the type of error in the source. There is no evidence of any systematic day/night difference in the uncertainty of the former mentioned gases, therefore there is also no day/night difference in uncertainty of $\mathrm{H}_{2} \mathrm{O}_{2}$.

The vertical resolution is described by the averaging kernel matrix (A) (Rodgers, 2000):

$\mathbf{A}=\left(\mathbf{K}^{T} \mathbf{S}_{\boldsymbol{y}}^{-1} \mathbf{K}+\mathbf{R}\right)^{-1} \mathbf{K}^{T} \mathbf{S}_{\boldsymbol{y}}^{-1} \mathbf{K}$

In case of $\mathrm{H}_{2} \mathrm{O}_{2}$ a rather strong regularization was applied to stabilize the retrievals. Therefore our averaging kernel (A) diagonal values are small and the resulting vertical resolution is quite low. In Fig. 6 representative averaging kernels are shown. Up to about $40 \mathrm{~km}$ the averaging kernels are wellbehaved, since they are rather symmetric and peak at their nominal altitude. Above $40 \mathrm{~km}$, information from above the nominal altitude contributes to the retrieval and thus the retrieval renders a distorted image of the true atmosphere. For $\mathrm{H}_{2} \mathrm{O}_{2}$ we only can use vmrs between about $20 \mathrm{~km}$ and $60 \mathrm{~km}$ height. The corresponding vertical resolution, which is the full width at half maximum of an averaging kernel row in a specific height, is about $8 \mathrm{~km}$ in the lower stratosphere and increases to about $35 \mathrm{~km}$ in the upper stratosphere. During polar night, when the temperatures are lower, the vertical resolution becomes even worse, while during polar day, 


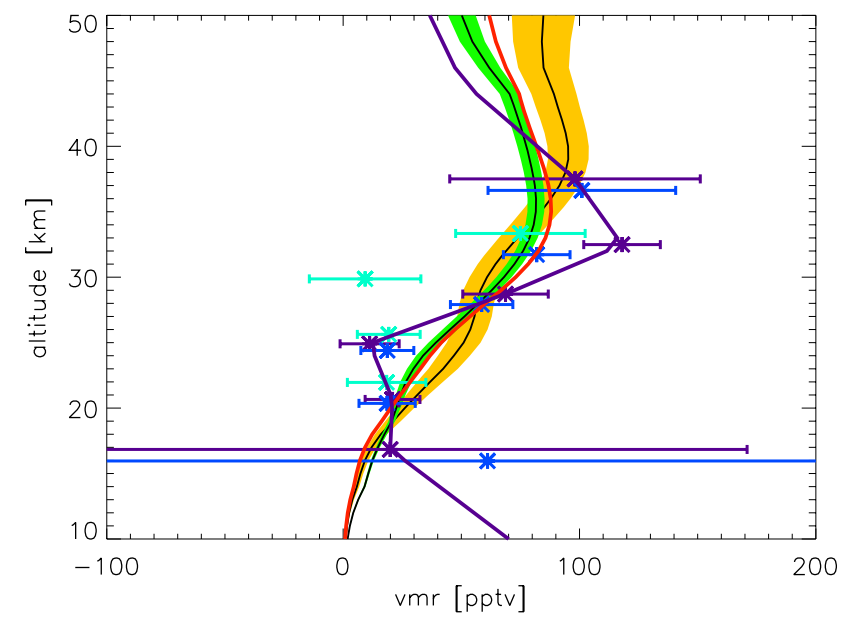

Fig. 7. Comparison of $\mathrm{H}_{2} \mathrm{O}_{2}$ balloon-borne observations (Chance et al., 1996) (asterisks: September 1989; violet: afternoon; blue: night; light blue: morning) and MIPAS observations (yellow: September 2002; green: September 2003) all showing 1-sigma error bars; balloon measurements were made above Fort Sumner $\left(34.5^{\circ} \mathrm{N}\right)$, while MIPAS measurements are zonal means between $30^{\circ} \mathrm{N}$ and $40^{\circ} \mathrm{N}$. The solid violet line is the interpolated balloonborne profile, while the red line is the violet profile convolved with the MIPAS A.

the vertical resolution is better. Comparison of $\mathrm{H}_{2} \mathrm{O}_{2}$ MIPAS measurements with models must be done by application of the MIPAS A to the model results. The result is the modeled $\mathrm{H}_{2} \mathrm{O}_{2}$ distribution as it would be seen by MIPAS.

\subsection{Comparison with other measurements}

In order to put our measurements into context we compared to balloon-borne $\mathrm{H}_{2} \mathrm{O}_{2}$ profiles, and the $\mathrm{H}_{2} \mathrm{O}_{2}$ distributions retrieved from MIPAS by Papandrea et al. (2005).

Chance et al. (1996) performed a balloon-borne measurement of $\mathrm{H}_{2} \mathrm{O}_{2}$ in the far infrared spectral range in September 1989 in Fort Sumner in New Mexico (34.5 $\mathrm{N})$. They measured a vmr of $118 \pm 16 \mathrm{pptv}$ at $32.5 \mathrm{~km}$ at a balloon flight in the afternoon and $82 \pm 14$ pptv at $31.7 \mathrm{~km}$ during night. On the following morning they measured $75 \pm 27 \mathrm{pptv}$ in $33.3 \mathrm{~km}$ altitude. In September 2002 zonal mean vmrs from MIPAS data reach from $71 \pm 13$ to $97 \pm 10 \mathrm{pptv}$ in an altitude of $32 \mathrm{~km}$ between latitudes of $32.5^{\circ} \mathrm{N}$ and $37.5^{\circ} \mathrm{N}$. In September 2003 the vmrs cover a range from $71 \pm 10$ to $86 \pm 12$ pptv. Thus MIPAS vmr of $\mathrm{H}_{2} \mathrm{O}_{2}$ seems to be lower than the balloon-borne measurements. Figure 7 compares the balloon-borne measurement with our MIPAS results, including 1-sigma error bars and considering the different vertical resolution by applying the MIPAS As to the balloon-borne profiles (red line). Within the error bars and considering the inter-annual variability above $35 \mathrm{~km}$ which is obvious from the 2002 and 2003 mean profiles, the two measurements are in good agreement.
Another balloon-borne measurement of hydrogen peroxide in the far infrared spectral range is available from Park and Carli (1991). Their measurement took place in June 1983 over Texas. They retrieved a mean vmr of about $130 \mathrm{pptv}$ in an altitude of $30 \mathrm{~km}$ for a 5-km-thick layer. The estimated error is $60 \%$. Within the error bars this measurement is in agreement with our retrieved vmr.

Kaye and Jackman (1986) inferred mixing ratios of $\mathrm{H}_{2} \mathrm{O}_{2}$ from several measured profiles of other trace gases not including $\mathrm{HO}_{\mathrm{x}}$ with the help of a chemistry model. They derived higher vmr in the summer hemisphere and highest vmr around equinox which both is in agreement with our observations. However their vmrs are much higher than the vmr obtained from MIPAS measurements, while they are comparable to our KASIMA model results (see Sect. 7).

Waters et al. (1981) obtained an abundance of $1.1 \pm 0.5 \mathrm{ppbv}$ from a balloon-borne microwave sounder. This value is much higher than our retrieved result or the results from other balloon-borne measurements. However, they described their results as tentative.

In comparison to the MIPAS results by Papandrea et al. (2005) we have in general a lower vertical resolution in the uppermost stratosphere and lower mesosphere but a higher vertical resolution below. Their volume mixing ratios in the mid-latitudes are about the same as ours. Their maximum values in the tropics reach vmrs above $330 \mathrm{pptv}$, which is much higher than our maximum of about $130 \mathrm{pptv}$ at the same time. This can partly be explained by different vertical resolutions. A quantitative analysis, however, could not be performed since the vertical resolutions vary differently with altitude, and simply convolving the profiles by Papandrea et al. (2005) with the As of our retrievals or vice versa would not adequately take into account the different retrieval characteristics.

\section{Results and comparison with model}

We analyzed the data for 190 days between September 2002 and March 2004 for all of which MIPAS full resolution measurements were available. For the comparison with the model we applied the corresponding MIPAS A to the model profiles. Only profiles within $350 \mathrm{~km}$ and $2 \mathrm{~h}$ of a MIPAS geolocation were considered. For detailed comparison we have chosen an altitude of $30 \mathrm{~km}$. This height is near the maximum of the volume mixing ratio profile. In addition the errors in terms of standard error of the mean are lowest at altitudes between 30 and $40 \mathrm{~km}$ with a value of 10 pptv. Below this altitude the errors are slightly higher, above they increase to values up to $80 \mathrm{pptv}$ in $55 \mathrm{~km}$ in the Northern Hemisphere summer. 

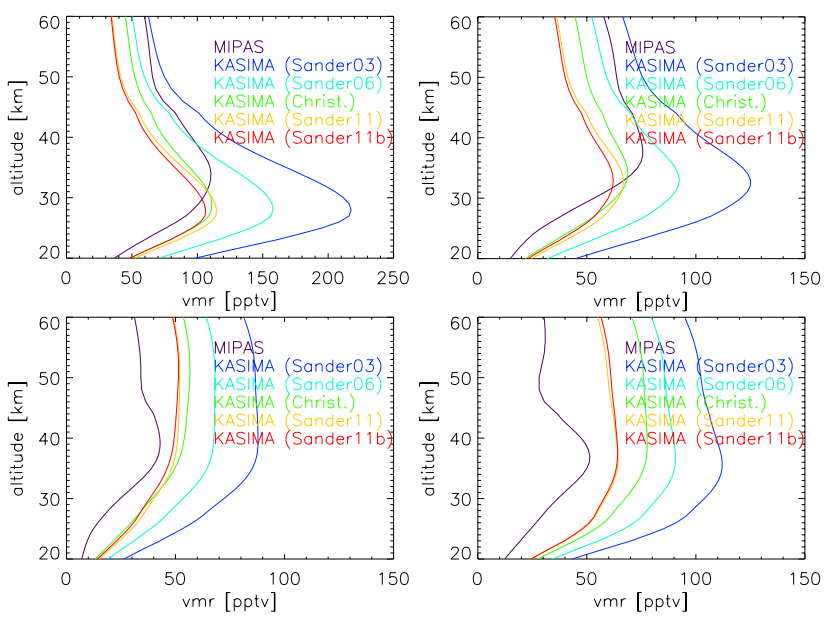

Fig. 8. Mean profiles for MIPAS measurements (purple) and KASIMA model results with MIPAS A applied with JPL recommendation for R1 from Sander et al. (2003) (blue), Sander et al. (2006) (turquoise), Christensen (green), Sander et al. (2011) (orange) and Sander et al. (2011) with updated $\mathrm{HO}_{\mathrm{x}}$ reactions (red); top left: $20^{\circ} \mathrm{S}$ to $20^{\circ} \mathrm{N}$; top right: $30^{\circ} \mathrm{N}$ to $60^{\circ} \mathrm{N}$; bottom left: $70^{\circ} \mathrm{N}$ to $90^{\circ} \mathrm{N}$; bottom right: $70^{\circ} \mathrm{S}$ to $90^{\circ} \mathrm{S}$.

\subsection{Sensitivity to the $\mathrm{HO}_{2}+\mathrm{HO}_{2}$ reaction}

There is a large difference in absolute vmr between KASIMA default model run with the reaction rate for R1 from Sander et al. (2003) and MIPAS with almost twice as much $\mathrm{H}_{2} \mathrm{O}_{2}$ in KASIMA than in MIPAS. The reason for this difference is not completely understood but there are some hints. Sensitivity tests show that the $\mathrm{H}_{2} \mathrm{O}_{2} \mathrm{vmr}$ is rather sensitive to a different photolysis rate of $\mathrm{H}_{2} \mathrm{O}_{2}$ in KASIMA and to different reaction rates for $\mathrm{HO}_{2}+\mathrm{HO}_{2}$, and thus uncertainties of the corresponding reaction rates may contribute to the difference between observations and model. For example Christensen et al. (2002) suggest a much different reaction rate for (R1) compared to Sander et al. (2003). For the temperature conditions in the middle stratosphere, the reaction rate according to Christensen et al. (2002) is only about half the value of Sander et al. (2003). In Fig. 8 the results from five KASIMA model runs, one with the reaction rate from Christensen et al. (2002), one with the reaction rate from Sander et al. (2003), one with the reaction rate from Sander et al. (2006), one with the reaction rate from Sander et al. (2011) and one with all $\mathrm{HO}_{\mathrm{x}}$ reaction rates changed to Sander et al. (2011) are compared to MIPAS observations. The figure covers the whole time period of the high resolution MIPAS measurements of $\mathrm{H}_{2} \mathrm{O}_{2}$. With the recommended reaction rate from Sander et al. (2003) the mixing ratio in the model is higher than observed by MIPAS in the whole altitude range and in each latitude bin. Up to about $30 \mathrm{~km}$ there is a factor of about 2 between these two mean profiles in the tropics. Above $30 \mathrm{~km}$ the difference is decreasing to almost perfect match in about $60 \mathrm{~km}$. If we use the updated reaction rate from Sander et al. (2006) the agreement in general becomes better but $\mathrm{H}_{2} \mathrm{O}_{2}$ mixing ratios in the model are still too high. In midlatitudes the mixing ratio in general is smaller and in higher altitudes the difference remains higher. In the polar regions the difference between observation and model result is growing with altitude upto a factor of three. If the reaction rate from Christensen et al. (2002) is used, modelled results are closer to MIPAS observations. In the tropics and midlatitudes the maximum vmrs are about the same in the model run and in the observations but the maximum in the model is about $5 \mathrm{~km}$ lower in altitude. In the upper stratosphere the model now produces too low vmr. The vmr in the polar regions are reduced in all altitudes compared to the Sander et al. (2003) and Sander et al. (2006) reaction rates, but remain too high in comparison to MIPAS observations. Using reaction rate from Sander et al. (2011) gives very similar results to Christensen et al. (2002). Biggest influence can be seen in southern polar region where the mixing ratios are getting closer to MIPAS observations. Changing all other $\mathrm{HO}_{\mathrm{x}}$ reactions in KASIMA to Sander et al. (2011) (red profile in Fig. 8) has only a very small impact on our model results.

For all the following model results we show the results from our KASIMA model run with the reaction rate according to Christensen et al. (2002).

The model shows an additional maximum in $\mathrm{H}_{2} \mathrm{O}_{2} \mathrm{vmr}$ in the upper mesosphere (not shown). Highest vmrs there are up to 500 pptv. If we use reaction rate from Sander et al. (2003) the maximum is much more pronounced (vmr upto 4000 pptv). Unfortunately, the MIPAS measurement is not sensitive to $\mathrm{H}_{2} \mathrm{O}_{2}$ at these altitudes.

\subsection{Annual cycle}

Figure 9 presents a time-altitude cross section for inner tropics (top: MIPAS, bottom: KASIMA). It shows a seasonal variation and an interannual variation is indicated. The white areas indicate time periods and altitudes where the diagonal element of the $\mathbf{A}$ is below a threshold of 0.03. The highest vmrs are found in the middle stratosphere. In the altitude range between $25 \mathrm{~km}$ and $40 \mathrm{~km}$ an annual cycle is present. Highest vmrs are reached shortly after equinox in October and April (also see Fig. 10, top).

Now we take a closer look at an altitude of $30 \mathrm{~km}$. The temporal evolution of the $\mathrm{H}_{2} \mathrm{O}_{2}$ distribution in KASIMA (Fig. 10, middle) is very similar to the temporal evolution in the MIPAS measurements (Fig. 10, top). The time-latitude cross sections of daily means are calculated in latitude bins of 5 degrees. Both show the highest vmr in the inner tropics shortly after equinox. In the tropics and subtropics the $\mathrm{H}_{2} \mathrm{O}_{2}$ volume mixing ratio over the year is highest for lowest midday solar zenith angles. The lower volume mixing ratios at the end of 2003 and beginning of 2004 are represented by KASIMA as well. The described patterns do not change if we use reaction rates from Sander et al. (2003) to 

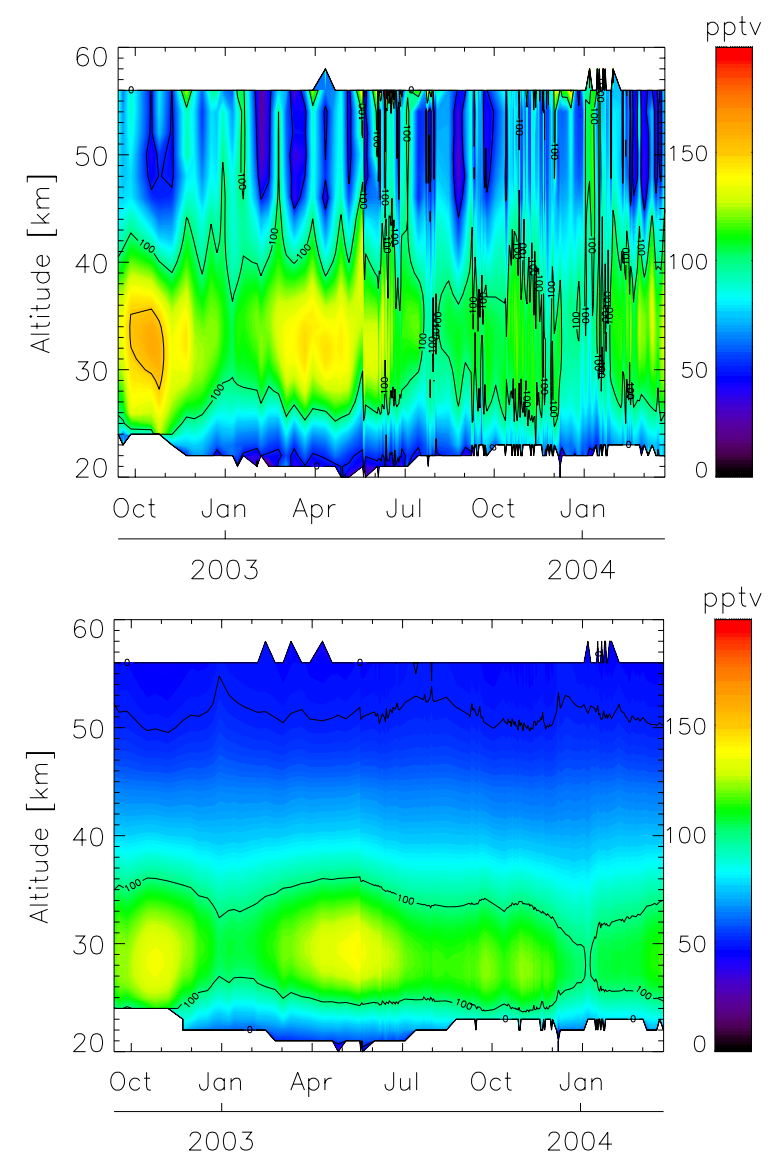

Fig. 9. Top: Timeseries of MIPAS $\mathrm{H}_{2} \mathrm{O}_{2}$ daily zonal mean vmr averaged between $10^{\circ} \mathrm{N}$ and $10^{\circ} \mathrm{S}$; Bottom: same for KASIMA results with MIPAS A applied

Sander et al. (2011) instead of the reaction rate from Christensen et al. (2002).

In the observations and in the model an interannual variability is present. Higher vmr are observed in the end of 2002 and in the beginning of 2003. This interannual variability can be assigned to a change in $\mathrm{OH}$ vmr. Our model produces higher $\mathrm{OH}$ vmr after the mid of 2003. As mentioned in the beginning of this paper $\mathrm{OH}$ is one of the main sinks of $\mathrm{H}_{2} \mathrm{O}_{2}$. OH itself for longer timeperiods is closely correlated with $\mathrm{H}_{2} \mathrm{O} . \mathrm{H}_{2} \mathrm{O}$ mixing ratios from MIPAS observations in an altitude of $30 \mathrm{~km}$ are shown in Fig. 10 (bottom). The vmrs until June 2003 in the inner tropics are lower than after June 2003. This change in the $\mathrm{H}_{2} \mathrm{O} \mathrm{vmr}$ is almost certainly due to a change in the QBO phase.

In the polar regions the volume mixing ratios are much lower in this altitude region. Shorter term changes in the mixing ratios there are not discussed in this paper because of possible influences by energetic particle precipitation. The overall discrepancy there between model and MIPAS observations (see also Fig. 10) are probably due to still unresolved
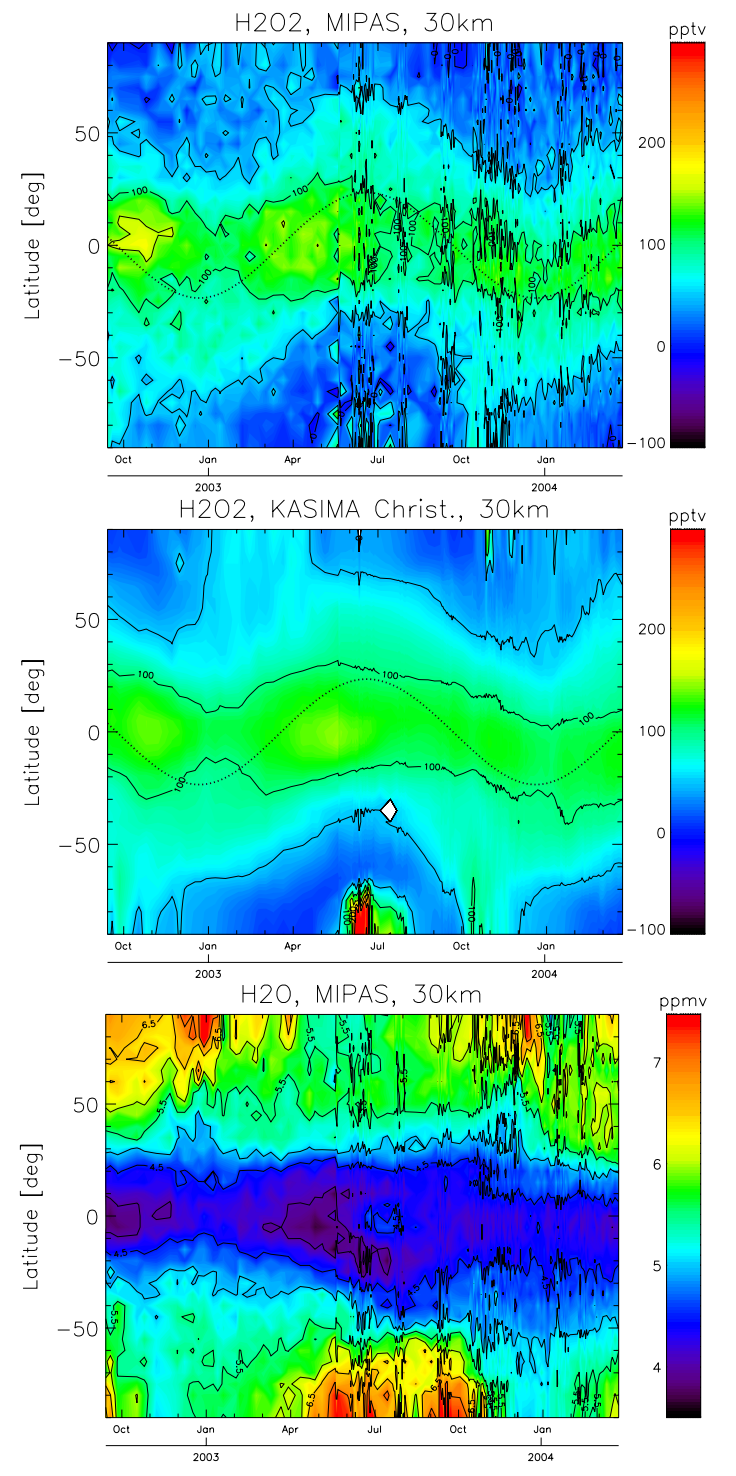

Fig. 10. Temporal evolution of the daily zonal means of the volume mixing ratio in $30 \mathrm{~km}$ of: (top) $\mathrm{H}_{2} \mathrm{O}_{2}$ as observed by MIPAS; (middle) $\mathrm{H}_{2} \mathrm{O}_{2}$ modeled by KASIMA with reaction rate constant from Christensen et al. (2002) for R1; vmr on MIPAS geolocations with MIPAS A applied; Additionally for $\mathrm{H}_{2} \mathrm{O}_{2}$ the latitude where the sun reaches zenith position for that day is shown (black dotted) (bottom) $\mathrm{H}_{2} \mathrm{O}$ as observed by MIPAS.

issues regarding reaction rates and related atmospheric conditions determining those.

\subsection{Diurnal cycle}

It is not possible to measure the full diurnal cycle with a satellite-instrument like MIPAS-ENVISAT because above the equator it only measures at $10 \mathrm{a} . \mathrm{m}$. and $10 \mathrm{p} . \mathrm{m}$. local time (LT). Therefore we present a day/night difference for MIPAS. For the comparison with KASIMA we reduced the allowed spatial difference to $250 \mathrm{~km}$ and the time difference to 


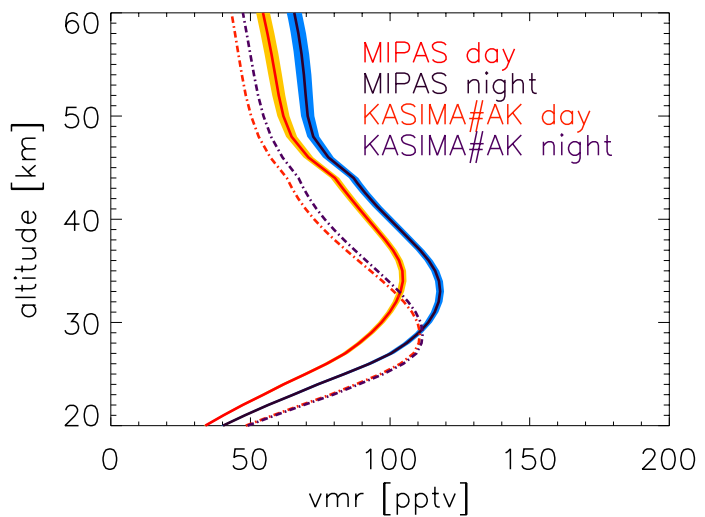

Fig. 11. Day (red) and nighttime (blue) $\mathrm{H}_{2} \mathrm{O}_{2}$ vmr for MIPAS (solid) and KASIMA with MIPAS A applied (dash-dotted) averaged between $20^{\circ} \mathrm{N}$ and $20^{\circ} \mathrm{S}$ for the full data period; For MIPAS the 3-sigma error bar is shown.

$1 \mathrm{~h}$. Profiles were averaged between $20^{\circ} \mathrm{N}$ and $20^{\circ} \mathrm{S}$. So we do not expect strong effects due to seasonal changes. To exclude such effects we also looked at smaller timeperiods and got the same results.

Figure 11 shows that the vmr for $\mathrm{H}_{2} \mathrm{O}_{2}$ in KASIMA are higher than in MIPAS in the lower stratosphere during day and night and are lower in the mid and upper stratosphere. The nighttime vmr measured by MIPAS is higher than MIPAS daytime vmr by about $15 \%$. The 3-sigma error bars do not overlap. The differences are significant on the $99 \%$ confidence level. The difference in KASIMA is much smaller and almost is not present but night values are also higher than day values.

The diurnal cycle of $\mathrm{H}_{2} \mathrm{O}_{2}$ as represented by the KASIMA model (no Averaging Kernel applied) in the tropics at $30 \mathrm{~km}$ altitude is shown in Fig. 12. Between 18:00 LT (sunset) and 06:00 LT (sunrise) local time, the $\mathrm{H}_{2} \mathrm{O}_{2}$ mixing ratio is almost constant. In the morning the vmr is decreasing until about 08:30LT. Afterwards the $\mathrm{H}_{2} \mathrm{O}_{2} \mathrm{vmr}$ is rising to its maximum at 14:30 LT. In the late afternoon the vmr is decreasing to its night value. Besides photolysis these changes can be attributed to $\mathrm{OH}$ and $\mathrm{HO}_{2}$ which both have very short lifetimes, are mainly influenced by sunlight and do change little during night.

The vmr of $\mathrm{H}_{2} \mathrm{O}_{2}$ in the model at 22:00 LT is higher than at 10:00 LT. The "diurnal cycle" therefore is in qualitatively good agreement between KASIMA model results and MIPAS measurements. There is also good agreement with the day/night variation shown by Papandrea et al. (2005), however they showed, for reasons not known, an even stronger "diurnal cycle" than in our MIPAS results. Chance et al. (1996) "did not see evidence for diurnal variation of $\mathrm{H}_{2} \mathrm{O}_{2}$ ". However, some hints that their results are in good agreement with our model results are presented in their paper. They performed three balloon measurements, one in the morning, one in the afternoon and one during night. In the morning they

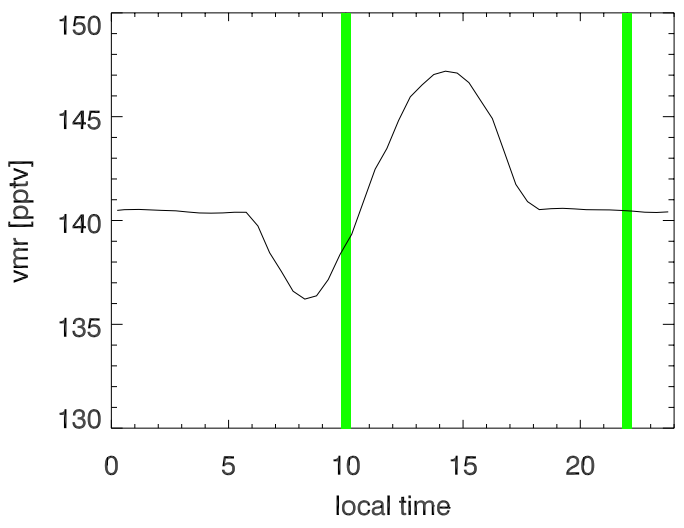

Fig. 12. Diurnal cycle of $\mathrm{H}_{2} \mathrm{O}_{2}$ vmr in KASIMA in dependency of local time in $30 \mathrm{~km}$; vmr is averaged for the whole data period between $10^{\circ} \mathrm{N}$ and $10^{\circ} \mathrm{S}$; The vertical lines mark MIPAS measurement times.

measured the lowest vmr and in the afternoon the highest. During night their measured vmr was in between. They had large error bars so the differences were not significant. But the temporal change of their mean values is in agreement with KASIMA model results.

While for MIPAS measurements in the whole altitude range the nighttime vmr is higher than daytime vmr, this is not the case for KASIMA. The diurnal cycle is modified at different altitudes in different ways. However, the $\mathrm{H}_{2} \mathrm{O}_{2}$ $\mathrm{vmr}$ at 22:00 LT is always higher than at 10:00 LT. Therefore the diurnal cycle in KASIMA is in good agreement with MIPAS measurements, however, the night-day-difference in KASIMA is smaller.

\section{Conclusions}

We have presented global distributions of $\mathrm{H}_{2} \mathrm{O}_{2}$ retrieved from MIPAS-Envisat spectra. The profiles cover an altitude range from about $20 \mathrm{~km}$ to $60 \mathrm{~km}$. The analysed data set consists of 190 days from September 2002 to March 2004. The total error for single profiles is very high but dominated by random error components which can be reduced by averaging. The retrieved profiles are qualitatively in good agreement with older balloon-borne measurements and with results from the 3D-CTM KASIMA. Potential reasons for the differences in the model are inappropriate reaction and photolysis rates. In a comparison of model runs with reaction rates for $\mathrm{HO}_{2}+\mathrm{HO}_{2} \longrightarrow \mathrm{H}_{2} \mathrm{O}_{2}+\mathrm{O}_{2}$ from Christensen et al. (2002) and Sander et al. (2003) the model performed much better with the first mentioned reaction rate. Our data shows highest vmr in the tropics in $30 \mathrm{~km}$. During the annual cycle, highest vmr is reached just after equinox. The absolute abundance of $\mathrm{H}_{2} \mathrm{O}_{2}$ in the tropics is driven by the $\mathrm{H}_{2} \mathrm{O}$ abundance and thus, is modulated, similar to $\mathrm{H}_{2} \mathrm{O}$, by the QBO; however, $\mathrm{H}_{2} \mathrm{O}_{2}$ vmrs are lower in the QBO phase when $\mathrm{H}_{2} \mathrm{O}$ 
provides higher values, due to $\mathrm{OH}$ produced from $\mathrm{H}_{2} \mathrm{O}$ as major $\mathrm{H}_{2} \mathrm{O}_{2}$ sink. The 10 a.m./10 p.m. differences observed by MIPAS can be qualitatively reproduced by the KASIMA model which shows a complicated diurnal cycle in the stratosphere. $\mathrm{H}_{2} \mathrm{O}_{2} \mathrm{vmr}$ is decreasing after sunrise and increasing in the late morning till afternoon. Using Sander et al. (2011) for $\mathrm{R} 1$ reaction rates gives very similar results to using reaction rates from Christensen et al. (2002). In our next paper we will discuss the influence of energetic particle events on $\mathrm{H}_{2} \mathrm{O}_{2}$ in polar regions.

Acknowledgements. We thank ESA for providing the MIPAS spectra (Level-1B data). This work was supported by the Priority Program CAWSES of the German science foundation (DFG) within the project MANOXUVA. We acknowledge support by Deutsche Forschungsgemeinschaft and Open Access Publishing Fund of Karlsruhe Institute of Technology.

Edited by: A. Richter

\section{References}

Ayers, G., Penkett, S., Gillett, R., Bandy, B., Galbally, I., Meyer, C., Elsworth, C., Bentley, S., and Forgan, B.: Evidence for photochemical control of ozone concentrations in unpolluted marine air, Nature, 360, 446-449, 1992.

Brasseur, G. P. and Solomon, S.: Aeronomy of the Middle Atmosphere - Chemistry and Physics of the Stratosphere and Mesosphere, Springer, P.O. Box 17, 3300 AA Dordrecht, The Netherlands, 3 edn., 2005.

Brian, H. and Prather, M. J.: Fast-J2: Accurate simulation of stratospheric photolysis in global chemical models, J. Atmos. Chem., 41, 281-296, 2002.

Chance, K., Traub, W. A., Johnson, D. G., Jucks, K. W., Ciarpallini, P., Stachnik, R. A., Salawitch, R. J., and Michelsen, H. A.: Simultaneous measurements of stratospheric HOx, NOx, and Clx: Comparison with a photochemical model, J. Geophys. Res., 101, 9031-9043, 1996.

Christensen, L. E., Okumura, M., Sander, S. P., Salawitch, R. J., Toon, G. C., Sen, B., Blavier, J.-F., and Jucks, K. W.: Kinetics of $\mathrm{HO}_{2}+\mathrm{HO}_{2} \rightarrow \mathrm{H}_{2} \mathrm{O}_{2}+\mathrm{O}_{2}$ : Implications for Stratospheric $\mathrm{H}_{2} \mathrm{O}_{2}$, Geophys. Res. Lett., 29, 1299-1302, 2002.

Fischer, H. and Oelhaf, H.: Remote sensing of vertical profiles of atmospheric trace constituents with MIPAS limb-emission spectrometers, Appl. Optics, 35, 2787-2796, 1996.

Fischer, H., Birk, M., Blom, C., Carli, B., Carlotti, M., von Clarmann, T., Delbouille, L., Dudhia, A., Ehhalt, D., Endemann, M., Flaud, J. M., Gessner, R., Kleinert, A., Koopman, R., Langen, J., López-Puertas, M., Mosner, P., Nett, H., Oelhaf, H., Perron, G., Remedios, J., Ridolfi, M., Stiller, G., and Zander, R.: MIPAS: an instrument for atmospheric and climate research, Atmos. Chem. Phys., 8, 2151-2188, doi:10.5194/acp-8-2151-2008, 2008.

Gallagher, M., Choularton, T., Downer, R., Tyler, B., Stromberg, I., Mill, C., Penkett, S., and Bandy, B.: Measurements of the entrainment of hydrogen peroxide into cloud systems, Atmos. Environ., 25A, 2029-2038, 1991.
Gnauk, T., Rolle, W., and Spindler, G.: Diurnal variations of atmospheric hydrogen peroxide concentrations in Saxony (Germany), J. Atmos. Chem., 27, 79-103, 1997.

Heikes, B., Kok, G., Welega, J., and Lazrus, A.: H2O2, O3 and SO2 measurements in the lower troposphere over the eastern United States during fall, J. Geophys. Res., 92, 915-931, 1987.

Holloway, A. M. and Wayne, R. P.: Atmospheric Chemistry, RSC Publishing, Cambridge, UK, 271 pp., 2010.

Kaye, J. A. and Jackman, C. H.: Concentration and Uncertainties of Stratospheric Trace Species Inferred From Limb Infrared Monitor of the Stratosphere Data. 2. Monthly Averaged $\mathrm{OH}, \mathrm{HO}_{2}$, $\mathrm{H}_{2} \mathrm{O}_{2}$, and $\mathrm{HO}_{2} \mathrm{NO}_{2}$, J. Geophys. Res., 91, 1137-1152, 1986.

Kiefer, M., von Clarmann, T., and Grabowski, U.: State parameter Data Base for MIPAS Data Analysis, Adv. Space Res., 30, 23872392, 2002.

Klee, S., Winnewisser, M., Perrin, A., and Flaud, J.-M.: Absolute Line Intensities for the $v_{6}$ Band of $\mathrm{H}_{2} \mathrm{O}_{2}$, J. Mol. Spectrosc., 195, 154-161, 1999.

Kouker, W., Offermann, D., Kuell, V., Reddmann, T., Ruhnke, R., and Franzen, A.: Streamers observed by the CRISTA experiment and simulated in the KASIMA model, J. Geophys. Res., 104, 405-418, 1999.

Lee, M., Heikes, B. G., Jacob, D. J., Sachse, G., and Anderson, B.: Hydrogen peroxide, organic hydroperoxide, and formaldehyde as primary pollutants from biomass burning, J. Geophys. Res. 102, 1301-1309, 1997.

Levenberg, A.: A method for the solution of certain non-linear problems in least squares, Q. Appl. Math., 2, 164-168, 1944.

Marquardt, D. W.: An algorithm for least-squares estimation of nonlinear parameters, J. Soc. Indust. Appl. Math., 11(2), 431-441, 1963.

Nett, H., Perron, G., Sanchez, M., Burgess, A., and Mossner, P.: MIPAS inflight calibration and processor validation, in: ENVISAT Calibration Review, Proc. of the European Workshop, ESA Publications Division, ESTEC, P.O. Box 299, 2200 AG Noordwijk, The Netherlands, 2002.

Olszyna, K. J., Meagher, J. F., and Bailey, E. M.: Gas-phase, cloud and rain-water measurements of hydrogen peroxide at a high-elevation site, Atmos. Environ., 22, 1699-1706, doi:10.1016/0004-6981(88)90398-8, 1988.

Papandrea, E., Dudhia, A., Grainger, R. G., Vancassel, X., and Chipperfield, M. P.: Retrieval of global hydrogen peroxide $\left(\mathrm{H}_{2} \mathrm{O}_{2}\right)$ profiles using ENVISAT-MIPAS, Geophiys. Res. Lett., 32, L14809, doi:10.1029/2005GL022870, 2005.

Park, J. H. and Carli, B.: Spectroscopic measurement of $\mathrm{HO}_{2}$, $\mathrm{H}_{2} \mathrm{O}_{2}$, and $\mathrm{OH}$ in the stratosphere, J. Geophys. Res., 96, 2253522541, 1991.

Perrin, A., Valentin, A., Flaud, J.-M., Camy-Peyret, C., Schriver, L., Schriver, A., and Arcas, P.: The 7.9- $\mu \mathrm{m}$ Band of Hydrogen peroxide: Line Positions and Intensities, J. Mol. Spectrosc., 171, 358-373, 1995.

Reddmann, T. and Uhl, R.: The H Lyman-a actinic flux in the middle atmosphere, Atmos. Chem. Phys., 3, 225-231, doi:10.5194/acp3-225-2003, 2003.

Reddmann, T., Ruhnke, R., and Kouker, W.: Three-dimensional model simulations of $\mathrm{SF}_{6}$ with mesospheric chemistry, J. Geophys. Res., 106, 525-537, 2001.

Remedios, J. J., Leigh, R. J., Waterfall, A. M., Moore, D. P., Sembhi, H., Parkes, I., Greenhough, J., Chipperfield, M. P., and 
Hauglustaine, D.: MIPAS reference atmospheres and comparisons to V4.61/V4.62 MIPAS level 2 geophysical data sets, Atmos. Chem. Phys. Discuss., 7, 9973-10017, doi:10.5194/acpd-79973-2007, 2007.

Rodgers, C. D.: Inverse Methods For Atmospheric Sounding - Theory And Practice, vol. 2, World Scientific, 2000.

Rothman, L. S., Jacquemart, D., Barbe, A., Benner, D. C., Birk, M., Brown, L. R., Carleer, M. R., Chackerian, Jr., C., Chance, K., Coudert, L. H., Dana, V., Devi, V. M., Flaud, J.-M., Gamache, R. R., Goldman, A., Hartmann, J.-M., Jucks, K. W., Maki, A. G., Mandin, J.-Y., Massie, S. T., Orphal, J., Perrin, A., Rinsland, C. P., Smith, M. A. H., Tennyson, J., Tolchenov, R. N., Toth, R. A., Vander Auwera, J., Varanasi, P., and Wagner, G.: The HITRAN 2004 molecular spectroscopic database, J. Quant. Spectrosc. Radiat. T., 96, 139-204, 2005.

Ruhnke, R., Kouker, W., and Reddmann, T.: The influence of the $\mathrm{OH}+\mathrm{NO}_{2}+\mathrm{M}$ reaction on the $\mathrm{NO}_{y}$ partitioning in the late Arctic winter 1992/1993 as studied with KASIMA, J. Geophys. Res., 104, 3755-3772, 1999.

Sander, S. P., Friedl, R. R., Ravishankara, A. R., Golden, D. M., Kolb, C. E., Kurylo, M. J., Huie, R. E., Orkin, V. L., Molina, M. J., Moortgat, G. K., and Finlayson-Pitts, B. J.: Chemical kinetics and photochemical data for use in atmospheric studies, Pasadena, CA, Jet Propulsion Laboratory, California Institute of Technology, JPL Publication 02-25, 2003.

Sander, S. P., Golden, D. M., Kurylo, M. J., Moortgat, G. K., Wine, P. H., Ravishankara, A. R., Kolb, C. E., Molina, M. J., FinlaysonPitts, B. J., Huie, R. E., and Orkin, V. L.: Chemical Kinetics and Photochemical Data for Use in Atmospheric Studies - Evaluation Number 15, Pasadena, CA, Jet Propulsion Laboratory, National Aeronautics and Space Administration, 2006.

Sander, S. P., Abbatt, J., Barker, J. R., Burkholder, J. B., Friedl, R. R., Golden, D. M., Huie, R. E., Kolb, C. E., Kurylo, M. J., Moortgat, G. K., Orkin, V. L., and Wine, P. H.: Chemical Kinetics and Photochemical Data for Use in Atmospheric Studies - Evaluation Number 17, Pasadena, CA, Jet Propulsion Laboratory, National Aeronautics and Space Administration, 2011.
Seinfeld, J. H. and Pandis, S. N.: Atmospheric chemistry and physics: from air pollution to climate change, A WileyIntersciencie publications, Wiley, 2006.

Slemr, F. and Tremmel, H.: Hydroperoxides in the marine troposphere over the Atlantic Ocean, J. Atmos. Chem., 19, 371-404, 1994.

Steck, T.: Methods for determining regularization for atmospheric retrieval problems, Appl. Opt., 41, 1788-1797, 2002.

Stiller, G. P., von Clarmann, T., Funke, B., Glatthor, N., Hase, F., Höpfner, M., and Linden, A.: Sensitivity of trace gas abundances retrievals from infrared limb emission spectra to simplifying approximations in radiative transfer modelling, J. Quant. Spectrosc. Radiat. Transfer, 72, 249-280, 2002.

Tikhonov, A.: On the solution of incorrectly stated problems and method of regularization, Dokl. Akad. Nauk. SSSR, 151, 501504, 1963.

von Clarmann, T. and Echle, G.: Selection of optimized microwindows for atmospheric spectroscopy, Appl. Opt., 37, 7661-7669, 1998.

von Clarmann, T., Glatthor, N., Grabowski, U., Höpfner, M., Kellmann, S., Kiefer, M., Linden, A., Mengistu Tsidu, G., Milz, M., Steck, T., Stiller, G. P., Wang, D. Y., Fischer, H., Funke, B., Gil-López, S., and López-Puertas, M.: Retrieval of temperature and tangent altitude pointing from limb emission spectra recorded from space by the Michelson Interferometer for Passive Atmospheric Sounding (MIPAS), J. Geophys. Res., 108, 4736, doi:10.1029/2003JD003602, 2003.

Waters, J. W., Hardy, J. C., Jarnot, R. F., and Pickett, H. M.: Chlorine Monoxide Radical, Ozone, and Hydrogen Peroxide: Stratospheric Measurements by Microwave Limb Sounding, Science, 214, 61-64, doi:10.2307/1687259, 1981. 